\title{
Evidence-based dexamethasone dosing in malignant brain tumors: what do we really know?
}

\author{
Charissa A. C. Jessurun ${ }^{1} \cdot$ Alexander F. C. Hulsbergen ${ }^{2,3,4} \cdot$ Logan D. Cho ${ }^{2,5} \cdot$ Linda S. Aglio $^{2,6} \cdot$ \\ Rishi D. S. Nandoe Tewarie ${ }^{3,4} \cdot$ Marike L. D. Broekman ${ }^{3,4,7}$
}

Received: 27 May 2019 / Accepted: 13 July 2019 / Published online: 25 July 2019

(c) The Author(s) 2019

\begin{abstract}
Purpose The present study aims to conduct a systematic review of literature reporting on the dose and dosing schedule of dexamethasone (DXM) in relation to clinical outcomes in malignant brain tumor patients, with particular attention to evidence-based practice.

Methods A systematic search was performed in PubMed, Embase, Web of Science, Cochrane, Academic Search Premier, and PsycINFO to identify studies that reported edema volume reduction, symptomatic relief, adverse events and survival in relation to dexamethasone dose in glioma or brain metastasis (BM) patients.

Results After screening 1812 studies, fifteen articles were included for qualitative review. Most studies reported a dose of $16 \mathrm{mg}$, mostly in a schedule of $4 \mathrm{mg}$ four times a day. Due to heterogeneity of studies, it was not possible to perform quantitative meta-analysis. For BMs, best available evidence suggests that higher doses of DXM may give more adverse events, but may not necessarily result in better clinical condition. Some studies suggest that higher DXM doses are associated with shorter survival in the palliative setting. For glioma, DXM may lead to symptomatic improvement, yet no studies directly compare different doses. Results regarding edema reduction and survival in glioma patients are conflicting.

Conclusions Evidence on the safety and efficacy of different DXM doses in malignant brain tumor patients is scarce and conflicting. Best available evidence suggests that low DXM doses may be noninferior to higher doses in certain circumstances, but more comparative research in this area is direly needed, especially in light of the increasing importance of immunotherapy for brain tumors.
\end{abstract}

Keywords Dexamethasone $\cdot$ Dosing $\cdot$ Glioma $\cdot$ Brain metastases $\cdot$ Evidence-based medicine

Charissa A. C. Jessurun and Alexander F. C. Hulsbergen: Shared first authorship.

Electronic supplementary material The online version of this article (https://doi.org/10.1007/s11060-019-03238-4) contains supplementary material, which is available to authorized users.

Marike L. D. Broekman

m.broekman@haaglandenmc.nl

1 Faculty of Medicine, University of Amsterdam/Amsterdam University Medical Center, Location Academic Medical Center (AMC), Meibergdreef 9, 1105 AZ Amsterdam, Noord-Holland, The Netherlands

2 Computational Neuroscience Outcomes Center (CNOC), Department of Neurosurgery, Brigham and Women's Hospital, Harvard Medical School, 75 Francis Street, Boston, MA 02115, USA

3 Department of Neurosurgery, Haaglanden Medical Center, Lijnbaan 32, 2512VA The Hague, Zuid-Holland, The Netherlands
4 Department of Neurosurgery, Leiden University Medical Center, Albinusdreef 2, 2333ZA Leiden, Zuid-Holland, The Netherlands

5 Brown University, 69 Brown Street, Providence, RI 02912, USA

6 Department of Anesthesiology, Perioperative and Pain Medicine, Brigham and Women's Hospital, Harvard Medical School, 75 Francis Street, Boston, MA 02115, USA

7 Department of Neurology, Massachusetts General Hospital, Harvard Medical School, 55 Fruit Street, Boston, MA 02114, USA 


\section{Background}

Dexamethasone (DXM) has been a staple of neurosurgical treatment for over half a century [1]. In the context of malignant brain tumors, it is used to control peritumoral edema and alleviate symptoms due to high intracranial pressure (ICP) or focal neurologic symptoms [2]. While symptomatic improvement is usually seen within 24 to $72 \mathrm{~h}[3,4]$, the use of DXM is associated with a variety of adverse events including muscular weakness, hyperglycemia, cushingoid symptoms, mental disorders, and gastrointestinal ulceration [3].

Despite the ubiquitous use of DXM for malignant brain tumors, evidence regarding the optimal dosing schedule is scarce. Doses are largely up to the discretion of treating physicians, leading to considerable practice variation $[3,5]$. As a result of the ongoing advances in immunotherapy for brain tumors, the potential risks versus benefits of immunosuppressants will likely face increased scrutiny. Therefore, it is vital to address the lack of standardization of DXM dosing in the immediate future. To elucidate this question, the present study aims to conduct a systematic review of literature reporting on dose and dosing schedule of DXM in relation to clinical outcomes in glioma and brain metastasis (BM) patients and critically assess the quality of evidence in relation to this question.

\section{Methods}

\section{Study design and search strategy}

A systematic search was performed in PubMed, Embase, Web of Science, Cochrane, Academic Search Premier, and PsycINFO on January 18, 2019. In addition, references of included studies were checked to identify additional relevant publications. Screening and data extraction were conducted by two independent reviewers (CJ and LC). In case of disagreement over inclusion, a third reviewer $(\mathrm{AH})$ was consulted. The complete search strategy can be found in Supplementary Material (S1 and S2).

\section{Inclusion criteria}

Randomized controlled trials (RCTs), prospective or retrospective cohorts or case-control studies, and case series with $>5$ patients were included. Publications reporting on the dose or dosing schedule of DXM in milligram per day $(\mathrm{mg} /$ day) in relation to clinical outcomes (symptomatic relief, adverse events, edema volume reduction, and survival) in patients with gliomas or BMs were included. Exclusion criteria were (1) non-human studies (2) other brain tumors including pituitary tumors and central nervous system lymphoma (3) only leptomeningeal metastases (4) combined regimens of DXM with immunotherapy or antiemetics (5) lack of relevant outcomes (6) imprecise description of dosing schedule (e.g., doses were not standardized and only the median or range of dosing was reported) (7) no full text available, and (8) non-English publications.

\section{Data extraction and analysis}

The following information was extracted: study characteristics including study design and sample size, patient characteristics including sex, age, baseline Karnofsky Performance Status (KPS), tumor characteristics including grade of glioma and primary tumor site for the metastases, and treatment characteristics including setting of DXM, DXM dosing and tapering schedules, and clinical outcomes. Outcomes were divided into four groups: (1) symptomatic relief (2) adverse events (3) edema volume reduction, and (4) survival. Extracted data were assessed for quantitative meta-analysis. A quality assessment of all included studies was performed based on the Cochrane Collaboration's tool [6] for assessing risk of bias for the RCTs and the Newcastle-Ottawa Scale (NOS) [7] for the nonrandomized studies. The level of evidence was assigned using the Oxford Centre for Evidence-Based Medicine by two independent reviewers ( $\mathrm{CJ}$ and $\mathrm{AH})[8]$.

\section{Results}

\section{Study selection and study characteristics}

Of 1812 publications identified by systematic search, thirteen met the inclusion criteria [2, 4, 9-19]. Two additional studies were identified by reference check $[20,21]$ for a total of fifteen articles (see Fig. S1).

Six studies reported on $>5$ glioma $[2,4,16-19]$ and twelve on > 5 BM patients $[4,9-16,19-21]$ (Table 2). None of the studies reported on leptomeningeal metastases. Two studies were RCTs [12, 14], one was a phase II pilot trial [21], and the rest were observational studies $[2,4,9-11,13,15-20]$. Four studies reported two or more DXM doses [9, 10, 12, $20]$, four reported dichotomized ranges $[11,14,15,19]$, and seven reported a single dose $[2,4,13,16-18,21]$ (Table 1). Doses varied between 4 and $96 \mathrm{mg} /$ day. The duration of DXM administration varied between one and 42 days. Three studies reported DXM monotherapy $[9,10,20]$, two studies reported perioperative schedules [4, 18], five described peri-radiotherapy treatment $[11-14,21]$, and five included a combination of multiple treatment settings [2, 15-17, 19]. Ten studies, including the RCTs, were conducted in the 1970s $[9,10,20], 1980$ s [15-17] and 1990s [12-14, 21] (Table 2).

Table 1 summarizes study and patient characteristics as well as critical assessment of evidence levels. Due to the low number of included studies and the heterogeneity of 
Journal of Neuro-Oncology (2019) 144:249-264

251

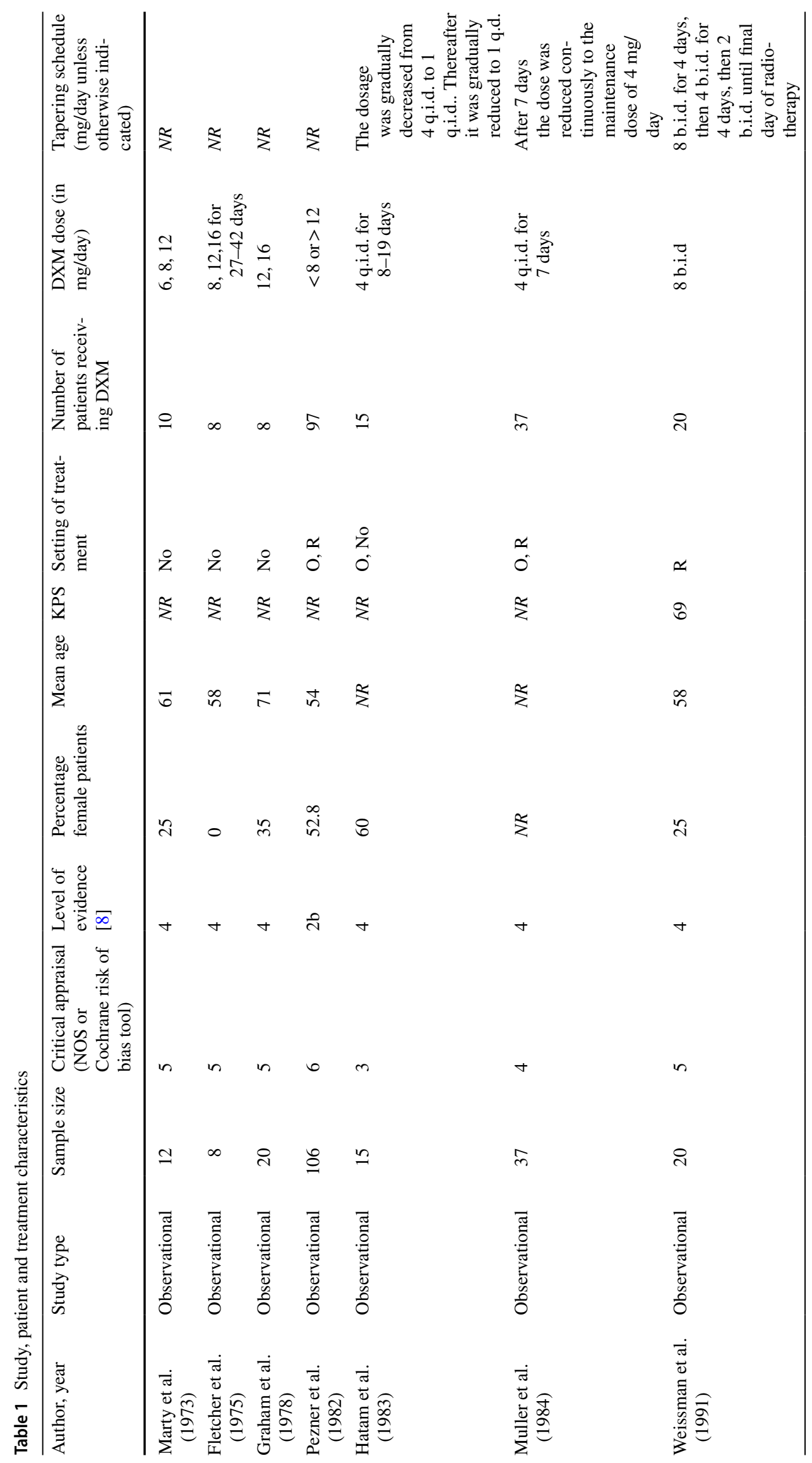

Springer 


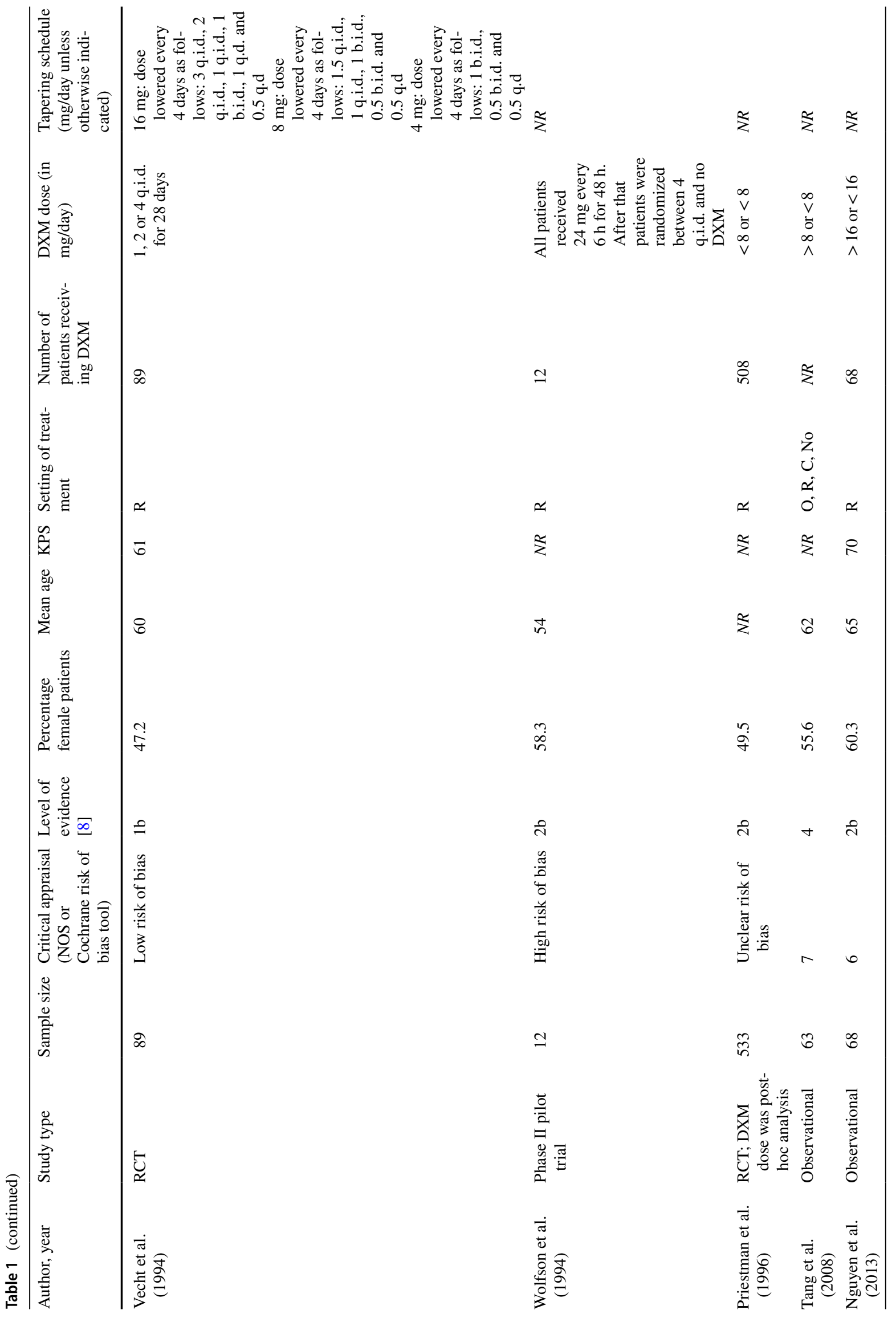




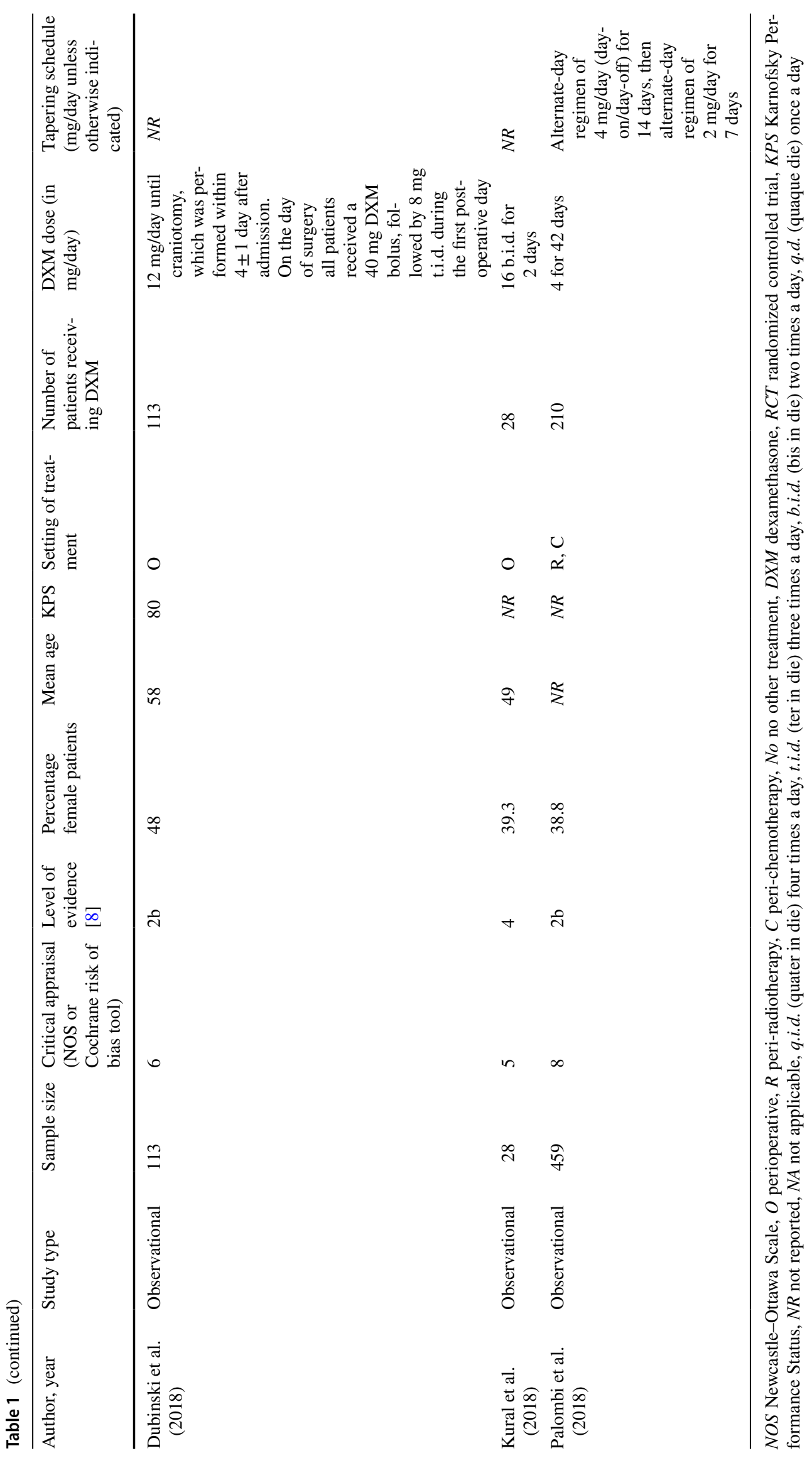




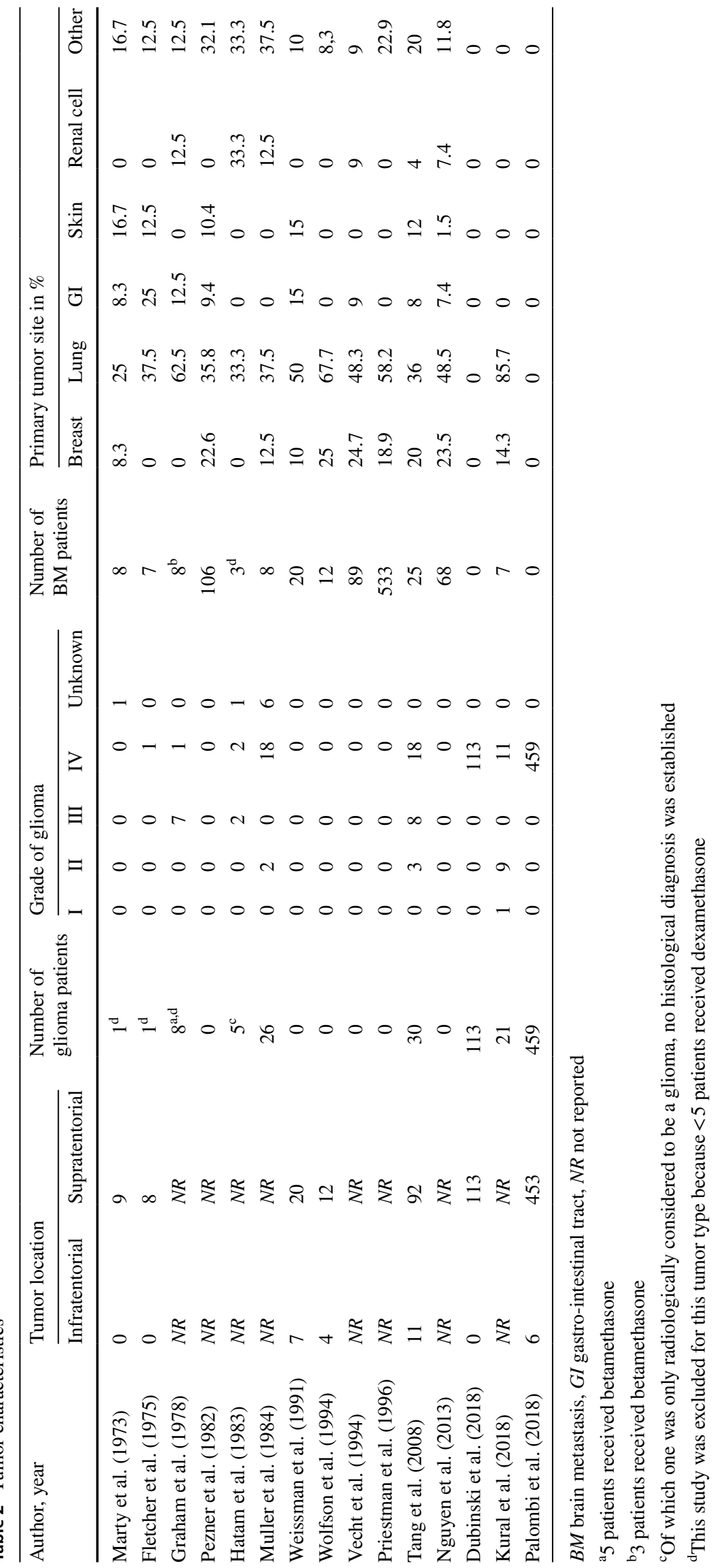


doses and reported outcomes per tumor type, quantitative meta-analysis was not performed.

\section{Glioma}

Six studies reported on the relationship between dosing of DXM and clinical outcomes in $>5$ glioma patients [2, 4, 16-19]. Table 3 summarizes the results of these studies.

\section{Symptomatic relief}

One study compared glioma patients receiving chemoradiation + DXM $4 \mathrm{mg} /$ day for six weeks $(\mathrm{n}=210)$ to patients only receiving chemoradiation $(n=249)$ [2]. Patients not receiving DXM suffered significantly more neurological symptoms due to cerebral edema than patients receiving DXM, including spatiotemporal disorientation, loss of coordination or balance, altered level of consciousness, loss of visual acuity, numbness or weakness, seizures, aphasia or dysarthria and headaches. No difference between groups

Table 3 Outcome characteristics per dose for glioma patients

\begin{tabular}{lll}
\hline Outcome category Author & $\begin{array}{l}\text { Level of } \\
\text { evidence }\end{array}$ & $\begin{array}{l}\text { Number of glioma patients/ number of patients receiving } \\
\text { nults }\end{array}$ \\
& DXM
\end{tabular}

Symptomatic relief Palombi et al. (2018) 2b 459/210

Edema Hatam et al. (1983) $4 \quad 5 / 5$

Muller et al. (1984) $\quad 4 \quad 26 / 26$

Kural et al. (2018) $\quad 4 \quad 21 / 21$

$\begin{array}{llll}\text { Survival } & \text { Tang et al. (2008) } & 4 & 30 / 18\end{array}$

Dubinski et al. (2018) 2b $\quad$ 113/35
No DXM $(\mathrm{n}=249)$ vs. DXM $4 \mathrm{mg} /$ day for 42 days $(n=210)$, respectively:

Significant difference: more symptoms in no DXM group: spatial and temporal disorientation (11.6\% vs. $2.9 \% ; \mathrm{p}=0.001)$, loss of coordination or balance $(8 \%$ vs. $1.4 \% ; p=0.0003$ ), altered level of consciousness $(18,5 \%$ vs. $9.5 \% ; p=0.0013)$, loss of visual acuity $(9.2 \%$ vs. $2.9 \% ; \mathrm{p}=0.001)$, numbness or weakness ( $25.3 \%$ vs. $15.2 \%$; $\mathrm{p}=0.001)$, seizures $(20.9 \%$ vs $16.2 \% ; \mathrm{p}=0.001)$, aphasia or dysarthria $(32.9 \%$ vs. $8.1 \% ; \mathrm{p}=0.001)$ and headaches $(20 \%$ vs. $13.3 \%$; $\mathrm{p}=0.009$ )

No significant difference: nausea $(0.8 \%$ vs. $0.5 \%$; $\mathrm{p}=0.5)$, dizziness ( $2 \%$ vs. $1 \%$; $\mathrm{p}=0.25)$, incontinence $(0.4 \%$ vs. $0 \%$; $=0.31)$ and memory impairment $(6 \%$ vs. $3.8 \%$; $=0.14)$

DXM $4 \mathrm{mg}$ q.i.d. for eight to nineteen days $(\mathrm{n}=5)$ :

Edema volume pretreatment: $52 \mathrm{ml}$; edema volume posttreatment: $38.5 \mathrm{ml}$

$\rightarrow$ Mean edema volume reduction of $13.5 \mathrm{ml}$ (26\%)

DXM 4 mg q.i.d. for seven days and then reduced to a maintenance dose of $4 \mathrm{mg} / \mathrm{day}(\mathrm{n}=26)$ :

Edema volume pretreatment: $20 \mathrm{~cm}^{2}$; edema volume posttreatment (after 20 days): $14 \mathrm{~cm}^{2}$

$\rightarrow$ The dimensions of edema volume did not change significantly

DXM $16 \mathrm{mg}$ b.i.d. for two days $(\mathrm{n}=21)$ :

Edema volume pretreatment: $3.01 \mathrm{ml}$; edema volume posttreatment: $2.96 \mathrm{ml}$

$\rightarrow$ Mean edema volume reduction of $0.05 \mathrm{ml}(1,7 \%)$ $(\mathrm{p}=0.76)$

Low-admission DXM ( $<8 \mathrm{mg} /$ day) versus highadmission DXM ( $>8 \mathrm{mg} /$ day $)(\mathrm{n}=18)$ :

DXM dose $>8 \mathrm{mg} /$ day predicted shorter survival (HR $5.60,95 \%$ CI $1.22-25.69 ; \mathrm{p}=0.027$ )

12 mg DXM preoperatively $(\mathrm{n}=35)$ versus no DXM preoperatively $(\mathrm{n}=78)$ :

No significant difference in OS nor PFS was observed between the two groups (HR 1.11, 95\%CI 0.74-1.66; $\mathrm{p}=0.605$ and HR 1.12, 95\% CI 0.71-1.77; $\mathrm{p}=0.605$, respectively)

DXM dexamethasone, $O S$ overall survival, PFS progression free survival, q.i.d. (quater in die) four times a day, b.i.d. (bis in die) two times a day 
was observed for nausea, dizziness, incontinence or memory impairment [2].

\section{Adverse events}

No study reported the relationship between DXM dosing and the frequency of adverse events in glioma patients.

\section{Edema}

Three studies reported the effect of DXM doses on peritumoral edema $[4,16,17]$. These studies were observational studies and did not specify a cut-off point for significant volumetric edema reduction. Two studies from the 1980s [16, 17] reported on volume reduction on computed tomography (CT) imaging, while only one study reported on magnetic resonance imaging (MRI)-assessed reduction [4]. In the first CT study, glioma patients receiving DXM $4 \mathrm{mg}$ four times a day (quater in die, q.i.d.) prior to surgery showed a mean edema volume reduction of $13.5 \mathrm{ml}$ after eight to nineteen days of treatment ( $26 \%$ of the pretreatment edema volume measured on CT scan with contrast) [17]. In contrast, the other two studies in patients receiving DXM 4 mg q.i.d [16] and $16 \mathrm{mg}$ two times a day (bis in die, b.i.d.) [4] showed no significant edema volume reduction after respectively 20 days and $48 \mathrm{~h}$ of DXM treatment.

\section{Survival}

Two studies reported survival in glioma patients [18, 19]. In eighteen glioblastoma patients admitted to a rehabilitation ward, a shorter survival was predicted by a high DXM dose of $>8$ versus $<8 \mathrm{mg} /$ day upon admission (HR 5.60, 95\% CI 1.22-25.69) [19]. In the second study [18], glioblastoma patients receiving $12 \mathrm{mg}$ DXM preoperatively $(\mathrm{n}=35)$ and patients without preoperative DXM were compared. All patients received $40 \mathrm{mg}$ perioperative DXM bolus followed by $24 \mathrm{mg}$ DXM during the first postoperative day. No significant difference in overall survival or progression free survival was observed between the two groups [18].

\section{Brain metastases}

Twelve studies [4, 9-16, 19-21] including two RCTs [12, 14] reported on the relationship between dosing of DXM and outcomes in $>5 \mathrm{BM}$ patients. Results are summarized in Table 4.

\section{Symptomatic relief}

Four small case series (5-20 patients) reported symptomatic relief, namely neurologic improvement $[9,10,13,20]$. DXM doses ranged from 6 to $16 \mathrm{mg} /$ day; the sample size of these studies limited statistical conclusions (Table 4).

One pilot prospective trial by Wolfson et al. reported twelve patients receiving $24 \mathrm{mg}$ DXM intravenously every $6 \mathrm{~h}$ for $48 \mathrm{~h}$ prior to radiotherapy [21]. Three patients had complete relief of neurologic and functional symptoms, one had a partial relief, and eight experienced no relief. During radiotherapy patients were randomized in $4 \mathrm{mg} / 6 \mathrm{~h}$ versus no DXM. No relief of clinical or neurologic symptoms were experienced in 6/7 and 4/5 patients of the DXM and control groups, respectively.

One RCT by Vecht et al. reported the dose-effect relationship between DXM initiated seven days prior to radiotherapy and KPS in two series [12]. In the first series $(n=42)$, no significant difference of improvement in KPS was observed in patients receiving DXM 8 versus $16 \mathrm{mg} /$ day after one week $(60 \%$ vs. $54 \%$ of the patients showed improvement, respectively; non-significant (NS)). At day $28,53 \%$ of the patients receiving $8 \mathrm{mg} /$ day and $81 \%$ of the patients receiving $16 \mathrm{mg} /$ day showed improvement in KPS (NS). In the second series $(n=47)$, no significant difference in KPS was seen in patients receiving DXM $4 \mathrm{mg} /$ day in comparison with $16 \mathrm{mg} /$ day at day seven and at day 28 [12].

\section{Adverse events}

Four studies reported adverse events in BM patients [11-13, 15]. In the RCT by Vecht et al., the incidence of cushingoid facies and ankle edema increased with the duration of treatment and with higher doses after one and four weeks $(\mathrm{p}<0.05)$, while other adverse events were not significantly affected [12]. A retrospective cohort study reported on 97 patients receiving DXM $\geq 12$ versus $\leq 8 \mathrm{mg} /$ day started at the time of diagnosis of BMs [15]. All patients received radiation and five patients underwent surgery as initial treatment. Of the patients receiving $\geq 12 \mathrm{mg}, 5.6 \%$ developed peptic ulcer disease, $6.7 \%$ hyperglycemia and $4.5 \%$ steroid myopathy in comparison with none of these adverse events in patients receiving $\leq 8 \mathrm{mg}$. In another series of twenty patients receiving $8 \mathrm{mg}$ b.i.d. for four days, then $4 \mathrm{mg}$ b.i.d. for four days and then $2 \mathrm{mg}$ b.i.d. until the final day of radiotherapy, five patients developed adverse events including hyperglycemia, candida esophagitis, peripheral edema, pseudo-rheumatism, and steroid withdrawal syndrome (all $\mathrm{n}=1$ ) [13]. The last study prospectively reported on 68 patients undergoing palliative whole-brain radiotherapy (WBRT) [11]. Patients receiving $\geq 16 \mathrm{mg} /$ day DXM reported more difficulty getting to sleep $(\mathrm{p}=0.009)$ but less nausea ( $\mathrm{p}$-value not reported) when compared to patients receiving $<16 \mathrm{mg} /$ day or no DXM two weeks after WBRT. No association was found between duration ( $<1 \mathrm{vs.} \geq 1$ week) of DXM treatment and adverse events. 
Table 4 Outcomes per dose for brain metastasis patients

\begin{tabular}{llll}
\hline Outcome category & Author & $\begin{array}{l}\text { Level of } \\
\text { evidence }\end{array}$ & $\begin{array}{l}\text { Number of BM patients/num- } \\
\text { ber of patients receiving DXM }\end{array}$
\end{tabular}

\begin{tabular}{llll}
\hline Symptom relief & Marty et al. (1973) & 4 & $8 / 8$
\end{tabular}
one showed no improvement

$8 \mathrm{mg} /$ day $(\mathrm{n}=2)$ : both patients showed neurological improvement

$12 \mathrm{mg} /$ day $(\mathrm{n}=3)$ : two patients showed neurological improvement, one showed no improvement

Fletcher et al. (1975) $\quad 4 \quad 7 / 7$

$8 \mathrm{mg} /$ day for ten days $(\mathrm{n}=2)$ : both patients showed neurological improvement after 10 days

$12 \mathrm{mg} /$ day for $2-3$ weeks $(\mathrm{n}=2)$ : one patient showed neurological improvement after 14 days and one patient showed neurological improvement after 8 days and 17 days

$16 \mathrm{mg} /$ day for $7-42$ days $(\mathrm{n}=3)$ : one patient showed neurological improvement after 6 weeks, one patient showed improvement after 12 days, and one patient showed improvement after 4 days, but then deteriorated after 9 and 14 days

$12 \mathrm{mg} / \mathrm{day}(\mathrm{n}=1)$ : the patient showed no neurological improvement

$16 \mathrm{mg} /$ day $(\mathrm{n}=4)$ : three patients showed neurological improvement, one patient showed no improvement

$16 \mathrm{mg} /$ day DXM $>24 \mathrm{~h}$ prior to the first dose of radiation $(\mathrm{n}=14)$ : seven patients (50\%) showed neurological improvement and seven patients $(50 \%)$ had neurological stabilization. No information on neurological improvement is available for the patients receiving DXM $<24 \mathrm{~h}$ prior to the first dose radiation $(\mathrm{n}=6)$

Fourteen patients completed the DXM treatment course as planned, three patients needed an increase in dose because of progressive neurologic symptoms, two patients showed tumor progression prompting an altered course and one patient developed hyperglycemia

Wolfson et al. (1994) $\quad 2 b \quad 12 / 12$

After 48 h $24 \mathrm{mg}$ every $6 \mathrm{~h}$ i.v. $(\mathrm{n}=12)$ : three patients $(25 \%)$ showed CR, one patient (8.3\%) showed PR, 8 patients $(66.7 \%$ ) showed NR

$4 \mathrm{mg}$ every $6 \mathrm{~h}$ versus no DXM treatment during radiotherapy:

$4 \mathrm{mg}$ every $6 \mathrm{~h}(\mathrm{n}=7)$ : for the post-radiotherapy change in GPS: one patient (14.3\%) deteriorated, four patients $(57.1 \%)$ showed no change, two patients (28.6\%) showed improvement. For the post-radiotherapy change in NFC: five patients $(71.4 \%)$ showed no change, one patient (14.3\%) showed improvement, one patient $(14.3 \%)$ deteriorated

No DXM $(n=5)$ : for the post-radiotherapy change in GPS: four patients $(80 \%)$ showed no change, one patient (20\%) deteriorated. The same numbers apply to the post-radiotherapy change in NFC

Vecht et al. (1994) $\quad$ 1b $\quad 89 / 89$

First series $(n=42): 8 \mathrm{mg} /$ day $(n=20)$ versus $16 \mathrm{mg} /$ day $(n=22)$

Day 7: 60\% of the patients in the 8-mg group showed improvement in KPS compared with $54 \%$ in the $16-\mathrm{mg}$ group $(\mathrm{RR}=1.1$; NS). Mean change in KPS is 8.0 (SD 10.1) versus 7.3 (SD 14.2)

Day 28: 53\% of the patients in the 8-mg group showed improvement in KPS compared with $81 \%$ in the 16-mg group $(\mathrm{RR}=0.67)$. Mean change in KPS is 6.7 (SD 18.4) versus 13.8 (SD 14.5)

Second series $(n=47): 4 \mathrm{mg} /$ day $(\mathrm{n}=24)$ versus $16 \mathrm{mg} /$ day $(\mathrm{n}=23)$ :

Day 7: 67\% of the patients in the 4-mg group showed improvement in KPS compared with 70\% in the 16-mg group $(\mathrm{RR}=0.96$; NS). Mean change in KPS is 6.7 (SD 11.3) versus 9.1 (SD 12.4)

Day 28: $62 \%$ of the patients in the 4-mg group showed improvement in KPS compared with $50 \%$ in the 16 -mg group $(\mathrm{RR}=1.2$; NS). Mean change in KPS is 7.1 (SD 18.2) versus 5.6 (SD 18.5) 
Table 4 (continued)

\begin{tabular}{|c|c|c|c|c|}
\hline Outcome category & Author & $\begin{array}{l}\text { Level of } \\
\text { evidence }\end{array}$ & $\begin{array}{l}\text { Number of BM patients/num- } \\
\text { ber of patients receiving DXM }\end{array}$ & Results \\
\hline Adverse events & Pezner et al. (1982) & $2 b$ & $106 / 97$ & $\begin{array}{l}\geq 12 \mathrm{mg} / \text { day }(\mathrm{n}=89) \text { versus } \leq 8 \mathrm{mg} / \text { day }(\mathrm{n}=8) \text { : } \\
\geq 12 \mathrm{mg} \text { /day: five out of } 89 \text { patients }(5.6 \%) \text { developed peptic ulcer } \\
\text { disease, six out of } 89 \text { patients }(6.7 \%) \text { hyperglycemia and four out } \\
\text { of } 89 \text { patients }(4.5 \%) \text { steroid myopathy } \\
\leq 8 \mathrm{mg} / \text { day: none of the adverse events mentioned above }\end{array}$ \\
\hline
\end{tabular}

Weissman et al. (1991) 4 20/2

Vecht et al. (1994) $\quad$ lb $\quad 89 / 89$

Nguyen et al. (2013) $\quad$ 2b $\quad 68 / 65$

Edema

Muller et al. (1984)

$8 / 8$

Kural et al. (2018)

4

$7 / 7$

Survival

Wolfson et al. (1994)

$2 \mathrm{~b}$

$12 / 12$

Priestman et al. (1996)

$2 b$

$533 / 508$

Tang et al. (2008)
$25 / 25$
Five patients receiving $8 \mathrm{mg}$ b.i.d. for four days developed adverse events including hyperglycemia $(\mathrm{n}=1)$, candida esophagitis $(n=1)$, peripheral edema $(n=1)$, pseudo rheumatism $(n=1)$ and steroid withdrawal syndrome $(\mathrm{n}=1)$

$4 \mathrm{mg} /$ day $(\mathrm{n}=24)$ versus $8 \mathrm{mg} /$ day $(\mathrm{n}=20)$ versus $16 \mathrm{mg} /$ day $(n=45)$ :

Significant difference: the occurrence of cushingoid facies and ankle edema increased with the duration of the treatment and higher doses $(\mathrm{p}=0.02$ at day 7 , and $\mathrm{p}=0.03$ at day 28)

No significant difference: raised glucose, raised blood pressure, infectious disease, gastrointestinal complaints, mental changes, proximal weakness

The mean KPS improvement was smaller in patients developing cushingoid facies, ankle edema or proximal weakness in comparison with patients without these symptoms. This suggests that a higher DXM dose is more effective in neurological improvement, but is associated with more adverse events which leads to a reduced net benefit on the KPS

$\geq 16 \mathrm{mg} /$ day $(\mathrm{n}=45)$ versus $<16 \mathrm{mg} /$ day $(\mathrm{n}=20)$ versus no DXM $(\mathrm{n}=3)$ :

Patients receiving $\geq 16 \mathrm{mg} /$ day DXM reported more difficulties getting to sleep $(\mathrm{p}=0.009)$ and less nausea on the DSQ in comparison with patient receiving $<16 \mathrm{mg}$ /day or no DXM at week 2 post-WBRT. No other items on the DSQ scale were significantly related to the DXM dose

Agitation/nervousness was associated with DXM duration of $\geq 1$ week ( $p=0.05)$. No association was found between the duration ( $\leq 1$ week or $\geq 1$ week) of DXM treatment and other DSQ scores

DXM 4 mg q.i.d. for seven days and then reduced to a maintenance dose of $4 \mathrm{mg} /$ day $(\mathrm{n}=8)$ :

Edema volume pretreatment: $25 \mathrm{~cm}^{2}$; edema volume posttreatment (after 20 days): $14 \mathrm{~cm}^{2}$

$\rightarrow$ mean reduction of $56 \%$ in the edema size (no p-value reported)

DXM $16 \mathrm{mg}$ b.i.d. for two days $(\mathrm{n}=7)$ :

Edema volume pretreatment: $1.52 \mathrm{ml}$; edema volume posttreatment: $1.57 \mathrm{ml}$

$\rightarrow$ No significant reduction of the edema volume $(\mathrm{p}=0.7)$

$24 \mathrm{mg}$ every $6 \mathrm{~h}$ for $48 \mathrm{~h}$ and then patients were randomized to $4 \mathrm{mg}$ every $6 \mathrm{~h}(\mathrm{n}=7)$ or no DXM $(\mathrm{n}=5)$ during radiotherapy:

Median survival of the study group of 4 months

1 -year OS of the study group: $16.7 \%$; 2 -year OS of the study group: $8.3 \%$

$\leq 8 \mathrm{mg} /$ day $(\mathrm{n}=183)$ versus $>8 \mathrm{mg} /$ day $(\mathrm{n}=325)$ :

$\leq 8 \mathrm{mg} /$ day: median survival of 96 days $(95 \% \mathrm{CI}$

$83-118) ;>8 \mathrm{mg} /$ day: median survival of 69 days $(95 \% \mathrm{CI}$ 61-79) $(\mathrm{p}=0.001)$

Low-admission DXM ( $<8 \mathrm{mg} /$ day) versus high-admission DXM $(>8 \mathrm{mg} /$ day $)(\mathrm{n}=25)$ :

DXM dose $>8 \mathrm{mg}$ /day predicted poor survival (HR $4.75,95 \% \mathrm{CI}$ $1.41-15.98 ; \mathrm{p}=0.012$ )

$B M$ brain metastasis, DXM dexamethasone, KPS Karnofsky performance status, DSQ DXM symptom questionnaire (used to assess 13 symptoms often associated with DXM toxicity), WBRT whole-brain radiotherapy, $N S$ not significant

q.i.d. (quater in die) four times a day, b.i.d. (bis in die) two times a day

$C R$ complete response, classified as the patient achieved a class 1 general performance status $(G P S$; class $1=$ normal) and neurologic function class (NFC; able to work or to perform normal activities. Neurological findings minor or absent). PR partial response, classified as the patient pertained to an upgrade of the GPS and/or NFC without either worsening. $N R$ nonresponse, defined as no change in both scores or a worsening of GPS and/or NFC without either improving 


\section{Edema}

Two studies reported the effect of DXM doses on edema in $\mathrm{BM}$ patients $[4,16]$. In eight patients receiving DXM $4 \mathrm{mg}$ q.i.d. for seven days and then a maintenance dose of $4 \mathrm{mg} /$ day prior to operation or radiotherapy, a reduction of $56 \%$ was seen in edema volume after 20 days of DXM treatment [16]. In contrast, in seven patients receiving DXM $16 \mathrm{mg}$ b.i.d. for two days perioperatively, no significant reduction of the edema volume was seen $(p=0.7)[4]$.

\section{Survival}

Three studies reported survival in BM patients [14, 19]. In an RCT of 533 patients receiving two different schedules of WBRT, DXM $\leq 8 \mathrm{mg} /$ day was associated with longer survival compared with $>8 \mathrm{mg} /$ day (median: 96 [95\% CI 83-118] vs. 69 days [95\% CI 61-79] respectively; $p=0.001$ ) [14]. Similarly, in 25 patients admitted to a rehabilitation ward after surgery, radiotherapy and/or chemotherapy, DXM dose $>8 \mathrm{mg} /$ day was associated with poorer survival (HR $4.75,95 \%$ CI 1.41-15.98; $\mathrm{p}=0.012$ ) [19]. Wolfson et al.'s pilot trial $(n=12)$ reported a median survival of 4 months. [21].

\section{Discussion}

This systematic review aimed to assess the available evidence supporting dosing schedules of DXM for glioma and BM patients. With the exception of one RCT in BM patients [12], we found there is very little evidence to support any claim regarding the optimal dosing of DXM in malignant brain tumors. The majority of included studies, including this RCT, were conducted in the 1970s [9, 10, 20], 1980s [15-17] and 1990s [12-14, 21], predating crucial advances in diagnostic and therapeutic modalities for brain tumors.

Most studies reported a dose of $16 \mathrm{mg}$, mostly in a schedule of $4 \mathrm{mg}$ q.i.d.[10, 12, 16, 17, 20]. This is congruent with a study by Sturdza et al. who reported that $45 \%$ of 34 surveyed physicians routinely prescribe DXM 4 mg q.i.d. in BM patients. The other respondents determined the dose according to the presence or absence of neurological symptoms [5].

For BMs, best available evidence suggests that higher doses of DXM may give more adverse events [11, 12, 15] but may not necessarily result in a better clinical condition (Oxford level 1b) [12]. Some studies suggest that higher doses of DXM are associated with shorter survival in a palliative setting $[14,19]$, but randomized studies that account for confounders, which would be necessary for causal inference, are lacking. For gliomas, less evidence is available still. While DXM may lead to symptomatic improvement [2], no studies directly compare different doses. Results regarding DXM's effect on edema reduction $[4,16,17]$ and survival $[18,19]$ are conflicting.

Several practice guidelines discuss dosing schedule of DXM in specific indications [22-26]; these are presented in Table 5. While these guidelines are partly based on each other, they report relatively wide ranges of starting doses (4-24 mg/day) and differ in recommendations for tapering schedules (3 days-2 weeks).

Dexamethasone dosing for other indications has been studied to varying degrees. A systematic review from 2016 [27] remarked a lack of high-quality evidence for the use of steroids in patients with metastatic spinal cord compression. The authors conclude that lower doses may be associated with similar clinical benefit and fewer adverse events when compared to higher doses. Another meta-analysis assessing impact of perioperative DXM on postoperative pain concluded that there was at best a small and clinically minimally significant dose-response relationship between DXM and pain scores [28]. A propensity score analysis of 26,634 neurosurgical patients in a national registry found preoperative steroid use to be associated with postoperative infections (odds ratio 1.38; 95\% CI 1.11-1.70), even after controlling for the presence of central nervous system tumors or chemotherapy treatment [29]. In contrast, a recent Cochrane systematic review of RCTs among all surgical specialties concluded that a single dose of perioperative DXM probably does not increase the risk of surgical site infections, while there was too little evidence to draw conclusions regarding delayed wound healing [30]. Neither the national registry study nor the Cochrane review reported dose-response relations.

Strengths of this review were its strict quality assessment and evidence-based focus. Moreover, only studies providing a specific dose of DXM in correlation with the studied outcome were included. This review was extensive as it included both gliomas and BMs. The major limitation of this review lies in the heterogeneity of underlying studies. Because the included articles varied in treatment setting, outcome parameters and dose standardization, quantitative meta-analysis was not possible. Several underlying studies are relatively old or report small sample sizes. Lastly, most included studies are retrospective, and some have poor quality assessment scores. It is therefore hard to determine whether the observed outcomes in these studies were truly the consequence of different DXM doses. These limitations to the original studies support our conclusions about the lack of evidence for this widely-used treatment.

Given the widespread use of DXM in the management of malignant brain tumors, this lack of evidence regarding optimal dosing schedules is surprising. Previous practice guidelines $[23,25,26]$ share the limitation that they are 


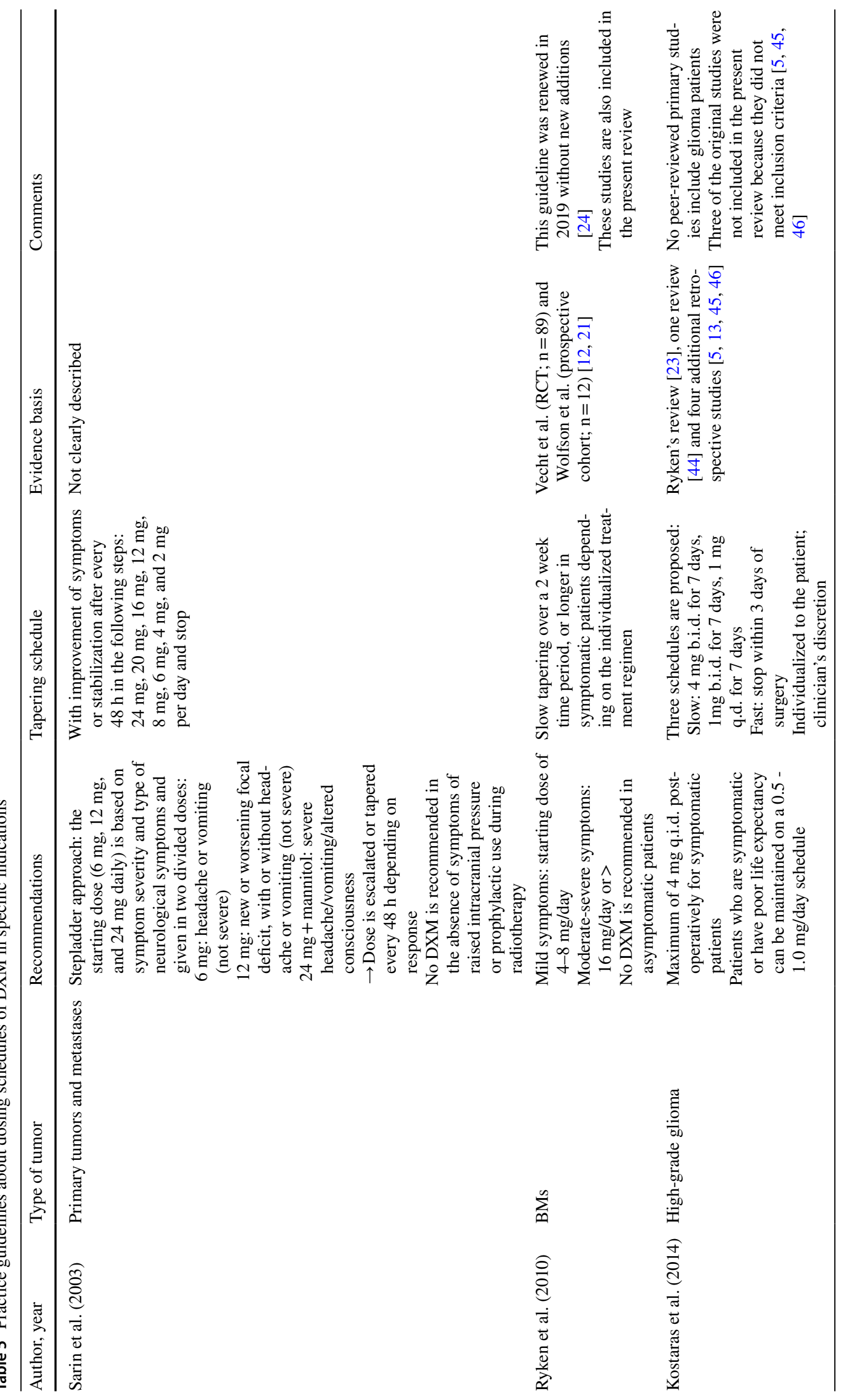


based on relatively few, poor-quality studies that infrequently describe dexamethasone doses in relation to outcomes that are comparable across studies. Moreover, the primary studies that they are based do not include glioma patients. Only recently have studies been published to address this question $[2,4,18]$. Level 1 evidence is not available for outcomes other than KPS improvement in patients that fit Vecht et al.'s [12] inclusion criteria. Of note, this excludes surgical patients, patients who received prior radiotherapy, patients older than 75 years, or patients with a KPS $\geq 90$, among others.

The pharmacodynamics and pharmacokinetics of DXM play a relevant role in the relationship between dosing and clinical outcomes. Pitter et al. [31] demonstrated that DXM administration was an independent indicator of shorter survival in mice and humans, although doses were not specified. The authors suggest that DXM-induced antiproliferative effects may confer protection from radiotherapy and chemotherapy-induced genotoxic stress. This could explain worse survival with higher DXM doses as seen in two included studies. Individual variation in response to DXM might be explained by polymorphisms of the glucocorticoid receptor gene [32, 33]. Moreover, anticonvulsants administered to brain tumor patients (e.g. valproate, carbamazepine, phenytoin, barbiturates) could induce or inhibit cytochrome P450 liver enzymes, influencing the clearance of DXM [26]. Lastly, individual variation in plasma free fraction could cause variation in (severity of) adverse events [32].

The biologic half-life of DXM is 34-54 h, suggesting doses may not have to be dosed four times a day [34]. In one included study, a twice-daily schedule provided good clinical improvement with minimal morbidity [13]. Moreover, the cumulative dose and duration of DXM largely determines corticosteroid toxicity [32]. Given the lack of clinical evidence for q.i.d. schemes and the aforementioned biological considerations, physicians should consider a twice daily scheme as a more patient-friendly and potentially safer alternative.

The effects of steroids and immunotherapies might counteract each other [35-38]. Recent evidence has indicated that BM patients treated with immunotherapies may have diminished survival if they are concurrently receiving corticosteroids [39, 40]. Moreover, recent evidence suggests steroids may have inherent metastasis-inducing properties [41]. Therefore, it is vital to assess the role of DXM with renewed scrutiny in anticipation of this ongoing paradigm shift in cancer treatment.

While it could be argued that the benefits of DXM in brain tumor patients are so obvious that evidence-based medicine is not the most appropriate approach for this question, Sarin et al. [22] have argued that the use of steroids in traumatic brain injury had an equally formidable reputation. However, 
in an RCT of $>10,000$ patients, steroids were found to have no benefit in this indication $[42,43]$.

Thus, there is a need for future investigation into dose-response relationships between DXM and several outcomes in both glioma and BM patients in different clinical settings. Studies should aim to prospectively compare different doses, dosing frequencies, and tapering schedules to determine which regimen yields the best balance between desired clinical effects and frequency of adverse events in specific patient subsets. With the current evidence in mind, the question whether lower doses are noninferior to $16 \mathrm{mg} /$ day in different scenarios is particularly worthy of exploration. Moreover, the interactions between DXM and immunotherapies should be studied in neurooncological patients.

\section{Conclusion}

Relatively little evidence is available regarding the optimal dosing scheme of DXM. In BMs, lower doses might be associated with similar efficacy and less adverse events than higher doses, but published data is heterogeneous. In gliomas, the lack of appropriate studies prevents drawing any conclusions based on more than expert opinion. The efficacy of different DXM doses is inadequately studied in the current literature; further investigation is needed to make evidence-based assessments and recommendations.

Acknowledgements The authors thank J.W. Schoones for his contribution to the systematic search in the different databases.

\section{Compliance with ethical standards}

Conflict of interest The authors declare that they have no conflict of interest.

Ethical approval This article does not contain any studies with human participants or animals performed by any of the authors

Open Access This article is distributed under the terms of the Creative Commons Attribution 4.0 International License (http://creativeco mmons.org/licenses/by/4.0/), which permits unrestricted use, distribution, and reproduction in any medium, provided you give appropriate credit to the original author(s) and the source, provide a link to the Creative Commons license, and indicate if changes were made.

\section{References}

1. Galicich JH, French LA, Melby JC (1961) Use of dexamethasone in treatment of cerebral edema associated with brain tumors. $\mathbf{J}$ Lancet 81:46-53

2. Palombi L, Marchetti P, Salvati M, Osti MF, Frati L, Frati A (2018) Interventions to reduce neurological symptoms in patients with GBM receiving radiotherapy: from theory to clinical practice. Anticancer Res 38:2423-2427. https://doi.org/10.21873 /anticanres. 12494

3. Drappatz J, Schiff D, Kesari S, Norden AD, Wen PY (2007) Medical management of brain tumor patients. Neurol Clin 25(10351071):ix. https://doi.org/10.1016/j.ncl.2007.07.015

4. Kural C, Atac GK, Tehli O, Solmaz I, Temiz C, Hodaj I, Izci Y (2018) The evaluation of the effects of steroid treatment on the tumor and peritumoral edema by DWI and MR spectroscopy in brain tumors. Neurol Neurochir Pol 52:495-504. https://doi. org/10.1016/j.pjnns.2018.03.002

5. Sturdza A, Millar BA, Bana N, Laperriere N, Pond G, Wong RK, Bezjak A (2008) The use and toxicity of steroids in the management of patients with brain metastases. Support Care Cancer 16:1041-1048. https://doi.org/10.1007/s00520-007-0395-8

6. Higgins J, Altman D (eds) (2008) Chapter 8: assessing risk of bias in included studies. Cochrane handbook for systematic reviews of interventions. The Cochrane Collaboration

7. Wells G, Shea B, O'Connell D, Peterson J, Welch V, Losos M, Tugwell P. The Newcastle-Ottawa Scale (NOS) for assessing the quality of nonrandomised studies in meta-analyses. https://www. ohri.ca/programs/clinical_epidemiology/oxford.asp

8. Medicine OCfE-b (2009) Oxford Centre for Evidence-based Medicine-Levels of Evidence (March 2009). https://www.cebm.net/

9. Marty R, Cain ML (1973) Effects of corticosteroid (dexamethasone) administration on the brain scan. Radiology 107:117-121. https://doi.org/10.1148/107.1.117

10. Fletcher JW, George EA, Henry RE, Donati RM (1975) Brain scans, dexamethasone therapy, and brain tumors. JAMA 232:1261-1263

11. Nguyen J, Caissie A, Zhang L, Zeng L, Dennis K, Holden L, Jon F, Tsao M, Danjoux C, Barnes E, Sahgal A, De Angelis C, Chow E (2013) Dexamethasone toxicity and quality of life in patients with brain metastases following palliative whole-brain radiotherapy. J Radiat Oncol 2:435-443

12. Vecht CJ, Hovestadt A, Verbiest HB, van Vliet JJ, van Putten WL (1994) Dose-effect relationship of dexamethasone on Karnofsky performance in metastatic brain tumors: a randomized study of doses of 4, 8, and $16 \mathrm{mg}$ per day. Neurology 44:675-680

13. Weissman DE, Janjan NA, Erickson B, Wilson FJ, Greenberg M, Ritch PS, Anderson T, Hansen RM, Chitambar CR, Lawton CA et al (1991) Twice-daily tapering dexamethasone treatment during cranial radiation for newly diagnosed brain metastases. $\mathrm{J}$ Neurooncol 11:235-239

14. Priestman TJ, Dunn J, Brada M, Rampling R, Baker PG (1996) Final results of the Royal College of Radiologists' trial comparing two different radiotherapy schedules in the treatment of cerebral metastases. Clin Oncol (R Coll Radiol) 8:308-315

15. Pezner RD, Lipsett JA (1982) Peptic ulcer disease and other complications in patients receiving dexamethasone palliation for brain metastasis. West J Med 137:375-378

16. Muller W, Kretzschmar K, Schicketanz KH (1984) CT-analyses of cerebral tumors under steroid therapy. Neuroradiology 26:293-298

17. Hatam A, Bergstrom M, Yu ZY, Granholm L, Berggren BM (1983) Effect of dexamethasone treatment on volume and contrast enhancement of intracranial neoplasms. J Comput Assist Tomogr 7:295-300

18. Dubinski D, Won SY, Gessler F, Quick-Weller J, Behmanesh B, Bernatz S, Forster MT, Franz K, Plate KH, Seifert V, Harter PN, Senft C (2018) Dexamethasone-induced leukocytosis is associated with poor survival in newly diagnosed glioblastoma. J Neurooncol 137:503-510. https://doi.org/10.1007/s11060-018-2761-4

19. Tang V, Rathbone M, Park Dorsay J, Jiang S, Harvey D (2008) Rehabilitation in primary and metastatic brain tumours: impact of functional outcomes on survival. J Neurol 255:820-827. https ://doi.org/10.1007/s00415-008-0695-z 
20. Graham K, Caird FI (1978) High-dose steroid therapy of intracranial tumour in the elderly. Age Ageing 7:146-150

21. Wolfson AH, Snodgrass SM, Schwade JG, Markoe AM, Landy H, Feun LG, Sridhar KS, Brandon AH, Rodriguez M, Houdek PV (1994) The role of steroids in the management of metastatic carcinoma to the brain. A pilot prospective trial. Am J Clin Oncol 17:234-238

22. Sarin R, Murthy V (2003) Medical decompressive therapy for primary and metastatic intracranial tumours. Lancet Neurol 2:357-365

23. Ryken TC, McDermott M, Robinson PD, Ammirati M, Andrews DW, Asher AL, Burri SH, Cobbs CS, Gaspar LE, Kondziolka D, Linskey ME, Loeffler JS, Mehta MP, Mikkelsen T, Olson JJ, Paleologos NA, Patchell RA, Kalkanis SN (2010) The role of steroids in the management of brain metastases: a systematic review and evidence-based clinical practice guideline. J Neurooncol 96:103114. https://doi.org/10.1007/s11060-009-0057-4

24. Ryken TC, Kuo JS, Prabhu RS, Sherman JH, Kalkanis SN, Olson JJ (2019) Congress of neurological surgeons systematic review and evidence-based guidelines on the role of steroids in the treatment of adults with metastatic brain tumors. Neurosurgery. https ://doi.org/10.1093/neuros/nyy546

25. Kostaras X, Cusano F, Kline GA, Roa W, Easaw J (2014) Use of dexamethasone in patients with high-grade glioma: a clinical practice guideline. Curr Oncol 21:e493-503. https://doi.org/10.3747/ co.21.1769

26. Ly KI, Wen PY (2017) Clinical relevance of steroid use in neuro-oncology. Curr Neurol Neurosci Rep 17:5. https://doi. org/10.1007/s11910-017-0713-6

27. Kumar A, Weber MH, Gokaslan Z, Wolinsky JP, Schmidt M, Rhines L, Fehlings MG, Laufer I, Sciubba DM, Clarke MJ, Sundaresan N, Verlaan JJ, Sahgal A, Chou D, Fisher CG (2017) Metastatic Spinal Cord Compression and Steroid Treatment: A Systematic Review. Clin Spine Surg 30:156-163. https://doi.org/10.1097/ BSD.0000000000000528

28. Waldron NH, Jones CA, Gan TJ, Allen TK, Habib AS (2013) Impact of perioperative dexamethasone on postoperative analgesia and side-effects: systematic review and meta-analysis. Br J Anaesth 110:191-200. https://doi.org/10.1093/bja/aes431

29. Merkler AE, Saini V, Kamel H, Stieg PE (2014) Preoperative steroid use and the risk of infectious complications after neurosurgery. Neurohospitalist 4:80-85. https://doi.org/10.1177/19418 74413510920

30. Polderman JA, Farhang-Razi V, Van Dieren S, Kranke P, DeVries JH, Hollmann MW, Preckel B, Hermanides J (2018) Adverse side effects of dexamethasone in surgical patients. Cochrane Database Syst Rev 11: CD011940. https://doi.org/10.1002/14651858. CD011940.pub3

31. Pitter KL, Tamagno I, Alikhanyan K, Hosni-Ahmed A, Pattwell SS, Donnola S, Dai C, Ozawa T, Chang M, Chan TA, Beal K, Bishop AJ, Barker CA, Jones TS, Hentschel B, Gorlia T, Schlegel U, Stupp R, Weller M, Holland EC, Hambardzumyan D (2016) Corticosteroids compromise survival in glioblastoma. Brain 139:1458-1471. https://doi.org/10.1093/brain/aww046

32. Ryan R, Booth S, Price S (2012) Corticosteroid-use in primary and secondary brain tumour patients: a review. J Neurooncol 106:449-459. https://doi.org/10.1007/s11060-011-0713-3

33. Huizenga NA, Koper JW, De Lange P, Pols HA, Stolk RP, Burger $\mathrm{H}$, Grobbee DE, Brinkmann AO, De Jong FH, Lamberts SW (1998) A polymorphism in the glucocorticoid receptor gene may be associated with and increased sensitivity to glucocorticoids in vivo. J Clin Endocrinol Metab 83:144-151. https://doi. org/10.1210/jcem.83.1.4490

34. Melby JC (1974) Drug spotlight program: systemic corticosteroid therapy: pharmacology and endocrinologic considerations. Ann Intern Med 81:505-512
35. Maxwell R, Luksik AS, Garzon-Muvdi T, Hung AL, Kim ES, Wu A, Xia Y, Belcaid Z, Gorelick N, Choi J, Theodros D, Jackson CM, Mathios D, Ye X, Tran PT, Redmond KJ, Brem H, Pardoll DM, Kleinberg LR, Lim M (2018) Contrasting impact of corticosteroids on anti-PD-1 immunotherapy efficacy for tumor histologies located within or outside the central nervous system. Oncoimmunology 7:e1500108. https://doi.org/10.1080/21624 02X.2018.1500108

36. Garant A, Guilbault C, Ekmekjian T, Greenwald Z, Murgoi P, Vuong T (2017) Concomitant use of corticosteroids and immune checkpoint inhibitors in patients with hematologic or solid neoplasms: a systematic review. Crit Rev Oncol Hematol 120:86-92. https://doi.org/10.1016/j.critrevonc.2017.10.009

37. Giles AJ, Hutchinson MND, Sonnemann HM, Jung J, Fecci PE, Ratnam NM, Zhang W, Song H, Bailey R, Davis D, Reid CM, Park DM, Gilbert MR (2018) Dexamethasone-induced immunosuppression: mechanisms and implications for immunotherapy. J Immunother Cancer 6:51. https://doi.org/10.1186/s4042 5-018-0371-5

38. Franchimont D (2004) Overview of the actions of glucocorticoids on the immune response: a good model to characterize new pathways of immunosuppression for new treatment strategies. Ann N Y Acad Sci 1024:124-137. https://doi.org/10.1196/annal s.1321.009

39. Margolin K, Ernstoff MS, Hamid O, Lawrence D, McDermott D, Puzanov I, Wolchok JD, Clark JI, Sznol M, Logan TF, Richards J, Michener T, Balogh A, Heller KN, Hodi FS (2012) Ipilimumab in patients with melanoma and brain metastases: an open-label, phase 2 trial. Lancet Oncol 13:459-465. https://doi.org/10.1016/ S1470-2045(12)70090-6

40. Kotecha R, Kim JM, Miller JA, Juloori A, Chao ST, Murphy ES, Peereboom DM, Mohammadi AM, Barnett GH, Vogelbaum MA, Angelov L, Suh JH, Ahluwalia MS (2019) The impact of sequencing PD-1/PD-L1 inhibitors and stereotactic radiosurgery for patients with brain metastasis. Neuro Oncol. https://doi. org/10.1093/neuonc/noz046

41. Obradović MMS, Hamelin B, Manevski N, Couto JP, Sethi A, Coissieux MM, Münst S, Okamoto R, Kohler H, Schmidt A, Bentires-Alj M (2019) Glucocorticoids promote breast cancer metastasis. Nature. https://doi.org/10.1038/s41586-019-1019-4

42. Roberts I, Yates D, Sandercock P, Farrell B, Wasserberg J, Lomas G, Cottingham R, Svoboda P, Brayley N, Mazairac G, Laloë V, Muñoz-Sánchez A, Arango M, Hartzenberg B, Khamis H, Yutthakasemsunt S, Komolafe E, Olldashi F, Yadav Y, MurilloCabezas F, Shakur H, Edwards P, Collaborators Ct (2004) Effect of intravenous corticosteroids on death within 14 days in 10008 adults with clinically significant head injury (MRC CRASH trial): randomised placebo-controlled trial. Lancet 364:1321-1328. https ://doi.org/10.1016/S0140-6736(04)17188-2

43. Edwards P, Arango M, Balica L, Cottingham R, El-Sayed H, Farrell B, Fernandes J, Gogichaisvili T, Golden N, Hartzenberg B, Husain M, Ulloa MI, Jerbi Z, Khamis H, Komolafe E, Laloë V, Lomas G, Ludwig S, Mazairac G, MeL Muñoz Sanchéz, Nasi L, Olldashi F, Plunkett P, Roberts I, Sandercock P, Shakur H, Soler C, Stocker R, Svoboda P, Trenkler S, Venkataramana NK, Wasserberg J, Yates D, Yutthakasemsunt S, Collaborators Ct (2005) Final results of MRC CRASH, a randomised placebo-controlled trial of intravenous corticosteroid in adults with head injury-outcomes at 6 months. Lancet 365:1957-1959. https://doi.org/10.1016/S0140 $-6736(05) 66552-X$

44. Millar BM, Bezjak A, Tsao M, Sturdza A, Laperriere N (2004) Defining the impact and contribution of steroids in patients receiving whole-brain irradiation for cerebral metastases. Clin Oncol 16(5):339-344

45. Hempen C, Weiss E, Hess CF (2002) Dexamethasone treatment in patients with brain metastases and primary brain tumors: do 
the benefits outweigh the side-effects? Support Care Cancer 10(4):322-328

46. Lagerwaard FJ, Levendag PC, Nowak PJCM, Eijkenboom WMH, Hanssens PEJ, Schmitz PIM (1999) Identification of prognostic factors in patients with brain metastases: a review of 1292 patients. Int J Radiat Oncol Biol Phys 43(4):795-803

47. Lo SSM, Gore EM, Bradley JD, Buatti JM, Germano I, Ghafoori AP, Henderson MA, Murad GJA, Patchell RA, Patel SH, Robbins JR, Robins HI, Vassil AD, Wippold FJ, Yunes MJ, Videtic
GMM (2014) ACR appropriateness criteria pre-irradiation evaluation and management of brain metastases. J Palliat Medicine 17(8):880-886

Publisher's Note Springer Nature remains neutral with regard to jurisdictional claims in published maps and institutional affiliations. 